

\section{Wind Energy and Power System Operations: A Review of Wind Integration Studies to Date}

Jennifer DeCesaro and Kevin Porter

Exeter Associates, Inc.

Columbia, Maryland

NREL Technical Monitor: J. Hein

Prepared under Subcontract No. LAM-9-99431-01

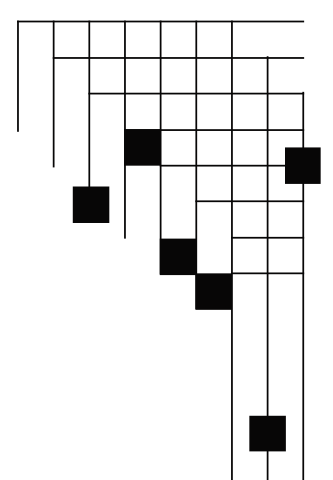




\section{NOTICE}

This report was prepared as an account of work sponsored by an agency of the United States government. Neither the United States government nor any agency thereof, nor any of their employees, makes any warranty, express or implied, or assumes any legal liability or responsibility for the accuracy, completeness, or usefulness of any information, apparatus, product, or process disclosed, or represents that its use would not infringe privately owned rights. Reference herein to any specific commercial product, process, or service by trade name, trademark, manufacturer, or otherwise does not necessarily constitute or imply its endorsement, recommendation, or favoring by the United States government or any agency thereof. The views and opinions of authors expressed herein do not necessarily state or reflect those of the United States government or any agency thereof.

Available electronically at http://www.osti.gov/bridge

Available for a processing fee to U.S. Department of Energy and its contractors, in paper, from:

U.S. Department of Energy

Office of Scientific and Technical Information

P.O. Box 62

Oak Ridge, TN 37831-0062

phone: 865.576 .8401

fax: 865.576 .5728

email: mailto:reports@adonis.osti.gov

Available for sale to the public, in paper, from:

U.S. Department of Commerce

National Technical Information Service

5285 Port Royal Road

Springfield, VA 22161

phone: 800.553 .6847

fax: 703.605.6900

email: orders@ntis.fedworld.gov

online ordering: http://www.ntis.gov/ordering.htm

This publication received minimal editorial review at NREL 


\section{Introduction}

Wind energy continues to be the fastest growing energy resource in the world. The U.S. wind industry installed 8,358 MW of new wind capacity in 2008, raising total U.S. wind capacity to just over 25,000 MW. ${ }^{1}$ Wind power's rapid expansion has been driven by a combination of its environmental benefits, various state and federal policies and incentives, and improving cost-competitiveness with other traditional generation technologies.

Certain natural characteristics of wind present challenges to power-system planners and operators. Wind plants operate when the wind blows, with power levels varying with the strength of the wind. Because of these characteristics, wind plants are not dispatchable in the traditional sense. As a result, the ability of system operators to control these plants while simultaneously maintaining the system's balance between load and generation is impaired.

To address these concerns, several different utilities have conducted studies on whether wind power can be integrated into the electric grid, and in some cases, at what cost. From 2003 through 2008, over a dozen integration studies were conducted across the United States. Moreover, the U.S. Department of Energy concluded that the United States can accommodate 20\% energy from wind generation by 2030 without the need for storage, assuming continued advances in transmission planning and grid operations. $^{2}$ The North American Electric Reliability Corporation (NERC) recently released a report suggesting that reliably incorporating high levels of variable resources (ocean, solar, and some types of hydropower, in addition to wind) will require changes to historic planning and operation methods for managing the grid.

This paper provides an overview of the challenges associated with wind integration and summarizes the findings of the wind integration studies conducted over the course of the past five years. We begin with an overview of the approximate time frames used in grid operations. We then describe how wind integration studies are conducted, discuss the results on wind integration costs and grid impacts from these grid integration studies, and assess some of the grid planning and operation changes that may be necessary to incorporate higher levels of wind generation. We close with several conclusions.

\section{Time Frames for Wind Impacts}

Wind integration studies typically divide grid operations into the following timeframes_regulation, load following, and unit commitment. While not exactly mimicking grid operation for every grid operator, it provides a useful framework for considering the potential impacts of wind integration over multiple timeframes.

The regulation time frame covers the period during which generation automatically responds to minuteby-minute deviations in load. Typically, a system operator will send signals to one or more generators to increase or decrease output to match the change in load. The regulation covers a time scale ranging from about several seconds to 10 minutes. Changes in load during the regulation time are typically not predicted or scheduled in advance and must be met with enough generation that is online and gridsynchronized to ensure the changes in load are met. 
The second time frame is load following, a longer period involving both capacity and energy. Generating units that have been previously committed, or can be started quickly, can provide this service, subject to physical constraints (e.g., state of the transmission system). The load following time frame covers periods ranging from 10 minutes to a few hours during which generating units are moved to different set points of capacity, subject to various operational and cost constraints, and in response to increasing load (in the morning) or decreasing load (late in the day). Load following is typically provided by generating units that are already committed or from generating units that can be started quickly, subject to operating constraints specific to the unit.

Unit commitment covers several hours to several days, and concerns the scheduling and committing of generation to meet expected electric demand. Generation in this time frame may require several hours, even days, to start-up and increase output to the preferred operating level. Similarly, taking a unit off-line may require several hours or days, and the unit may need several hours of cooling before restarting. Therefore, planning the "right" level of unit commitment is important. Scheduling too much generation may needlessly increase system operation costs, while scheduling too little generation may also increase costs by requiring the purchase of power at high market prices or running expensive, quick-start units. There may also be reliability issues if sufficient generation is not started or is not available on short notice.

\section{Wind Integration Studies}

In the United States, the majority of the wind integration studies have been prospective-looking at a potential future power system with wind - rather than retrospective-modeling what has actually happened. Generally, wind integration studies consist of multiple scenarios of steadily increasing wind penetration, starting with a base year and going into defined periods into the future while considering different levels of wind penetration. For electricity demand, either load forecasts are used, or past demand is scaled by a constant level (e.g., $1.5 \%$ per year). The studies assume transmission is built to meet future reliability needs and to accommodate higher wind penetration. Given the well-documented need for new transmission to interconnect remote renewable energy resources such as wind, the purpose of wind integration studies is to determine the operating impacts of adding large amounts of wind, not to serve as a transmission planning exercise.

For any wind integration study, it is imperative that the studies capture the coincidence of load and wind generation by ensuring wind and load generation data are from the same time period, as weather is a significant driver of both load and wind generation. Because wind integration studies are performed mostly on a prospective basis, wind data is typically not available at the beginning of the study. Wind generation data can be derived through large-scale, time-calibrated meteorological modeling that can recreate the weather coinciding to the time period(s) of historical load data that is used, and then converting the wind data to output using the power curve of wind turbines for the desired time period. ${ }^{3}$ Wind forecasts are simulated by statistical simulation or perturbations of model inputs or parameterization. Further research is needed to refine these approaches.

Two general approaches have been used to examine wind integration impacts in the United States. The first approach estimates the cost of increased reserves in the regulation, load-following, and unit commitment timeframes that are needed to balance the increased net load variability introduced by wind generation. These studies typically focus on wind's impact on ancillary services and compare wind with an energy-equivalent flat block of energy. The flat block will have no variability or uncertainty 
associated with it so that the operational differences can explicitly show these impacts. Although the flat block is a useful construct because of its inherent certainty and constant energy delivery, recent work has identified some weaknesses in this approach. Because the flat energy block is calculated to be the energy-equivalent to the wind, large inter-day ramps in this artificial benchmark unit can occur as a result of significant differences in day-to-day production between the wind energy and the flat block. This effect can be significant at high wind penetrations, and causes problems in the unit commitment and dispatch schedules inter-day. In addition, the flat block schedule tends to have more on-peak energy and less off-peak energy than wind generation. As a result, the daily flat block is worth $\$ 1.50$ to $\$ 2.00 / \mathrm{MWh}$ more than the wind generation, and the resulting estimated wind integration costs may be overstated. $^{4}$

The second approach does not directly calculate the cost of wind integration, but examines the impact that wind has on system commitment and dispatch, and calculates wind power's net value compared to fuel and other variable cost reductions. This approach will compare the wind case with that of an identical system without wind power and compare all contrasting impacts as incremental impacts of adding high penetrations of wind power. Although this does not separate the impacts of wind on various levels of reserves, those impacts are captured implicitly in the modeling framework and results.

\section{Common Findings}

Wind integration studies have evolved from "is it possible to integrate wind reliably" to focusing on the projected costs and actions necessary to integrate higher levels of wind generation with successive wind integration studies. As such, these studies have dispensed with several concerns with wind generation: that wind will need a MW-for-MW backup (not necessary because the grid balances total generation and load, not a single group of generators or technology); that wind generation will drop to zero in seconds (individual wind turbines in a wind project respond differently to wind resources, leading to an overall smoothing in output); and that wind projects may cause the electric grid to collapse (wind projects may improve grid performance if equipped with reactive power capability and other grid-friendly features).

Furthermore, projected costs to integrate wind appear to be reasonable. In general, at wind penetrations of up to $20 \%$ of system peak demand, wind integration costs will amount to about $10 \%$ or less of the wholesale value of the wind generation. Note that wind integration costs for independent system operators (ISOs) and regional transmission operators (RTOs) are typically lower than for non-ISOs and RTOs. One reason for these results is that ISOs and RTOs typically operate sub-hourly markets (i.e., they dispatch generation on a five- to fifteen-minute time frame), while many of the non-ISOs or RTOs require generators to follow hourly schedules and obtain all sub-hourly balancing from regulating units. 
Table 1. Key Results from Major Wind Integration Studies Completed 2003-2008.

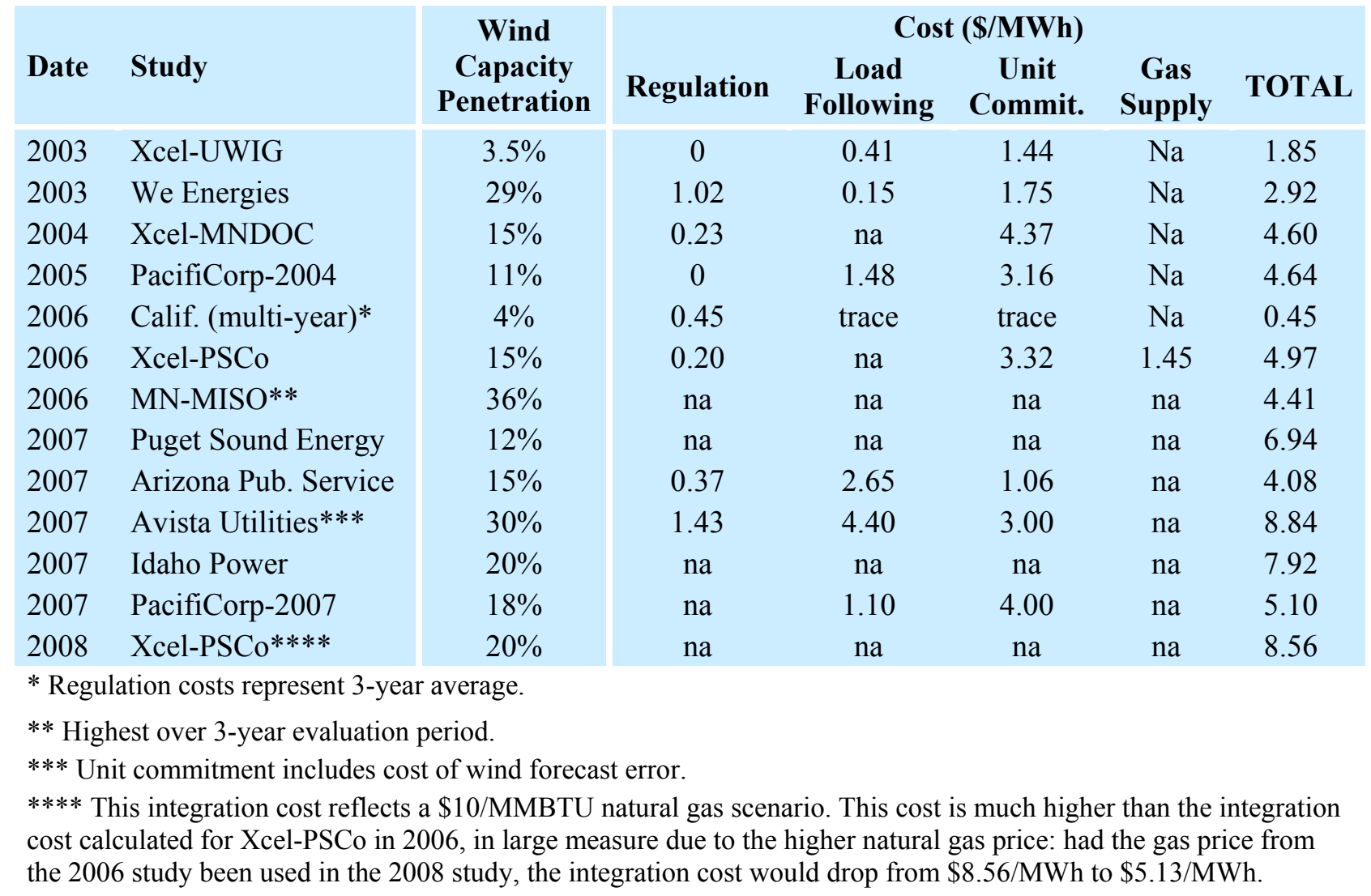

Source: Lawrence Berkeley National Laboratory, 2009; National Renewable Energy Laboratory, 2008.

By time frame of grid operation, U.S. integration studies have found that the impacts of wind power tend to increase with the time frame. Because the variations of load and wind tend to be uncorrelated in short time scales, most U.S. wind integration studies have found that only modest amounts of additional regulation are necessary with more wind. One exception is a 2007 study by the California ISO (CAISO), which assessed the feasibility of incorporating 6,000 MW of wind in the Tehachapi Pass Region in southern California. CAISO determined that regulation requirements would increase by nearly a factor of two, from $100 \mathrm{MW}$ to $170 \mathrm{MW}$, for "up" regulation (for generation to provide regulation when frequency is decreasing) and from $100 \mathrm{MW}$ to $500 \mathrm{MW}$ for "down" regulation (when generation must be ramped down because frequency is increasing and needs to be decreased). CAISO attributed this difference with other wind integration studies to the time lag in the generator's response to dispatch commands. ${ }^{5}$

U.S. wind integration studies have typically found a larger increase in the need for load following with higher levels of wind generation. This is due in large part to wind's diurnal output, which in many cases may be opposite of the peak demand period for electricity. For instance, wind output may fall off in the early morning hours when load is increasing, increasing the need for generating resources to ramp up to meet the increasing electric demand. Conversely, wind power production may be higher during off-peak hours when load is decreasing or at minimum levels, increasing the need for generating resources that 
can ramp down. Therefore, adding wind generation will typically require more load following to counteract the combined net variability of load and wind.

For the unit commitment time frame, wind generation introduces uncertainty in the day-ahead time frame of scheduling and committing generating units. This is the time scale that has the largest wind integration cost impacts, up to almost $\$ 9.00 / \mathrm{MWh}$ at wind capacity penetrations of up to $20 \%$ or $30 \%$. Unit commitment cost impacts are contingent on the amount of and characteristics of dispatchable generation resources, the amount of the wind forecast error (and interactions with the load forecast error), the market and regulatory environment, and the characteristics of the wind generation resource as compared to load. The uncertainty of wind power production in the unit commitment time frame may result in higher variable costs through increased fuel consumption and increased operating costs. This may occur if too much generation is committed due to underestimating wind production, or if not enough generation is committed because of overestimating expected wind generation, necessitating the use of quick start units, or short-term market purchases.

In addition, U.S. wind integration studies have also determined that certain periods will pose particular stress on grid generators: the morning load pick-up, when wind generation is typically ramping down while load is picking up, and times of low or minimum load, when wind production may be high when load is low. Because some of these potential impacts may be more pronounced by season, some grid operators are contemplating varying their regulation and load-following reserve requirements at different times of the year, in anticipation of different levels of wind output, as opposed to procuring a flat amount annually.

Overall, the variability of wind power generation adds to the variability on the grid in most time scales, and a key question that wind integration studies must address is whether there is enough existing capability on the grid to manage that increased variability, or whether new sources must be added to manage that variability. Finally, with larger levels of wind, the distribution of hourly changes in load widens, with more frequent events of higher hourly changes in load, both positive and negative, resulting in a potential need for more ramping capability. This point is illustrated in Figure 1 that compares the frequency of hourly changes in load with and without wind from a study that assessed the impacts of $25 \%$ wind generation in Minnesota. 
Figure 1. Load following impact of wind.

(Black shows no-wind case; gray shows net load and wind.)
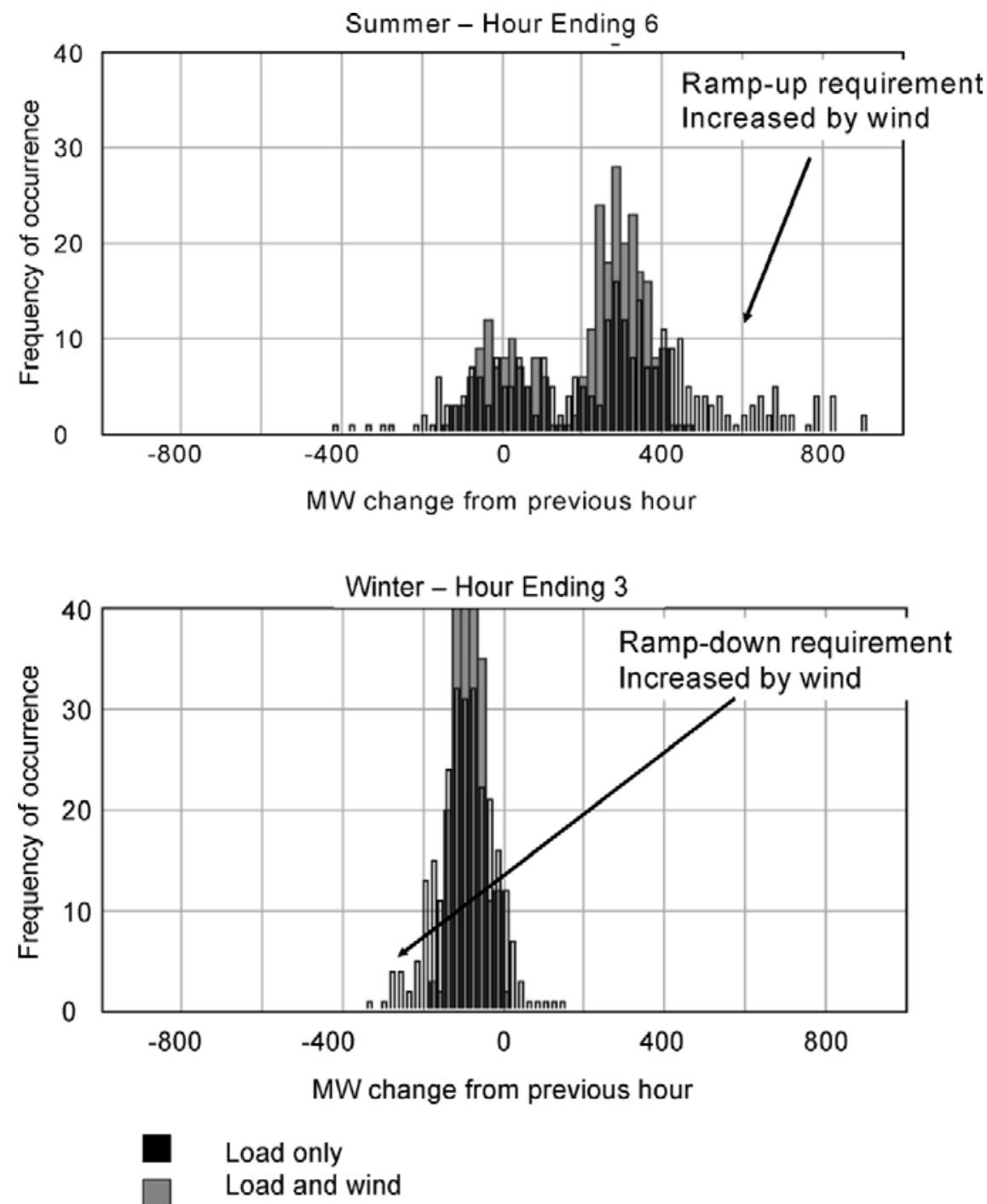

Source: Enernex Corporation and Wind Logics Inc., Wind Integration Study—Final Report, Prepared for Xcel Energy and the Minnesota Department of Commerce, September 28, 2004, http://www.uwig.org/XcelMNDOCStudyReport.pdf.

\section{Strategies for Incorporating Higher Levels of Wind Generation}

As noted earlier, 20\% of wind generation can be accommodated on utility grids - but not by doing more of the same. Grid planning and operations will need to change in order to reach higher levels of wind and other renewable energy generation, as discussed further below.

Transmission Additions and Upgrades

In general, high-quality wind resources are not located where the highest demand for electricity is, or in areas with a robust transmission infrastructure. Therefore, new transmission will be instrumental towards successfully integrating more wind generation. Wind power's need for transmission coincides 
with a widespread recognition among policymakers and the electric power industry that more transmission is necessary, not only to aid in wind integration, but also to maintain reliability and to access other generating resources in addition to wind. Correspondingly, there is an explosion of proposed transmission projects under various stages of planning and consideration, with over two dozen transmission projects under consideration in the western U.S. alone. ${ }^{6}$ Clearly, not all of these will be developed, and those that do proceed will not be ready for several years, but progress in this area will help immensely in wind integration.

\section{Deployment of Grid-Friendly Wind Plants}

The development of large grid-connected wind projects in the United States occurred first in California in the 1980s. Typically during those early years, wind projects were disconnected during a grid disturbance, and wind projects were not brought back on line until the grid was brought back to a normal state of operation. As wind energy generation increases, the deployment of grid-friendly wind plants will be vital. Modern wind turbines can and are capable of providing reactive support and power factor control, voltage ride-through, power curtailment and ramping control, primary frequency regulation, and inertia response.

\section{Balancing Areas}

The ease with which large amounts of wind power can be integrated into the electric system depends in large part on the size of the balancing area. Consolidating balancing areas into larger entities, accessing a larger balancing area through the use of dynamic scheduling, or implementing shared area control error or energy imbalances among multiple control areas act to facilitate the integration of larger amounts of wind into the system. Larger balancing areas also increase load diversity, which reduces the magnitude of the peak load with respect to installed generation capacity. In a similar vein, larger balancing areas help provide greater geographic wind diversity, which smoothes wind production and reduces the magnitude and frequency of extreme changes in wind production. ${ }^{7}$ Ultimately, this serves to reduce the number of hours during which the most expensive units in the dispatch queue will be operating, subsequently reducing the operating reserve requirement and costs.

\section{$\underline{\text { Wind Forecasting }}$}

Because of the variability and uncertainty of wind production, a common practice for grid operators and utilities historically in the United States has been to simply take the wind generation on an as-available basis and back off other generation that has been committed in order to incorporate the wind generation. In general, such practices are acceptable for installed wind generation amounting to small percentages of peak load, as the variability of the wind generation is swamped by load variability and could be easily absorbed. Such practices become untenable at higher levels of wind penetration, as it imposes operational inefficiencies and increased fuel consumption that becomes significant as wind penetration increases. A General Electric (GE) study assessing the potential grid impacts of $10 \%$ wind penetration determined that the variable operating cost savings increase from $\$ 335$ million to $\$ 430$ million when state-of-the-art wind forecasting is used, with another $\$ 25$ million in benefits when perfect wind forecasting is used. ${ }^{8}$ The Intermittency Analysis Project conducted by GE for the California Energy Commission demonstrated a benefit of $\$ 4.37 / \mathrm{MWh}$ with state-of-the-art wind forecasting and another $\$ 0.95 / \mathrm{MWh}$ for perfect wind forecasting. ${ }^{9}$ Moreover, it is not only important to implement wind forecasting, but to incorporate it into control room operations to ensure that wind forecasting is accounted for in scheduling and dispatch decisions. It also will be important for wind forecasting 
systems to be able to successfully predict large wind ramps to allow utilities and RTOs to prepare for those events when they occur.

The Electricity Reliability Council of Texas (ERCOT) and the New York ISO (NYISO) implemented central wind forecasting systems in 2008. PJM and the Midwest ISO will also implement a central wind forecasting system in 2009. They join CAISO, which implemented the nation's first central wind forecasting system in 2002; CAISO is in the process of expanding and improving their system. In addition, Xcel Energy is collaborating with the National Center for Atmospheric Research and the National Renewable Energy Laboratory (NREL) in developing high-resolution wind forecasts every three hours for wind projects in Colorado, Minnesota, New Mexico, Texas, and Wyoming.

New Market Features and Products

Market and policy changes will likely be a necessary feature of accessing greater flexibility from either new or existing generation units, and that may take a combination of expanded ancillary service markets, incentives, and market requirements. In Texas, the GE-ERCOT study made an overarching recommendation that both day ahead and shorter term forecasts be used as the basis for ancillary service procurement. With respect to specific services, the study recommended that ERCOT consider introducing a new non-spinning reserve service with a startup time of 10 to 15 minutes. This service has the potential to reduce the amount of responsive reserves needed for identified periods of wind generation drop risk. With respect to regulation service, the study recommended that forecast data be used to adjust regulation service procurements for each hour on a day-ahead basis. ${ }^{10}$

Further market or policy changes may be necessary to accommodate large-scale wind ramps, which are relatively slow and infrequent and occur over several hours, as compared to a sudden generator trip. As such, wind ramps more closely resemble large load ramps than sudden unscheduled generator outages or trips. The ancillary service requirements from large wind ramps are more closely aligned with nonspinning reserves and supplemental operating reserve that are provided by generators and responsive loads that can respond within 10 to 30 minutes. Yet current reliability rules in the United States require nonspinning reserves and supplemental operating reserves to only be in service for a period of time (usually 1 to 2 hours) that is shorter than the wind ramps that may occur over a longer period of several hours. Because of that, system operators may follow large wind ramps with regulation, at a cost that is 10 to 40 times that of non-spinning reserves and supplemental operating reserves. By way of comparison, nonspinning and supplemental operating reserves are estimated to cost about $\$ 1.50 / \mathrm{MWh}$ on average in California and New York in 2008, while regulation costs ranged between \$33/MWh and \$60/MWh. ${ }^{11}$

\section{Increasing Operational Flexibility}

Adding variable generation sources will increase the need for generation resource flexibility, i.e., the ability for generation to move up and down in response to changing net load as opposed to baseload resources that have long start-up and shut-down times and are most cost-efficient and cost-effective when running at full output. Generation resource flexibility will be needed at different time scales. The need for resource flexibility is more pronounced during times of minimum load, when generation that can be cycled down will be valued in order to accommodate higher levels of wind generation, as well as during times of low wind production, whereby generation that can ramp up will be needed. This can be accomplished through adding flexible sources of new generation or from garnering more flexibility from existing generators. 
That said, while operational flexibility is of high value to grid operators, it has correspondingly little value for power suppliers unless compensated, as deeper turn-back, more rapid cycling and load following, and more frequent starts and stops all cause higher costs and revenue reductions for generation suppliers. Market and policy changes will likely be necessary for achieving greater amounts of flexible generating resources and may take a combination of expanded ancillary service markets, incentives, and market requirements.

\section{Faster Markets}

Fast, sub-hourly energy markets will also aid in integrating greater amounts of wind power and at a reduced cost. Sub-hourly energy markets can tap flexibility from existing generating units at little or no cost, and reduce the need for regulation, the most costly ancillary service. It also matches the timing of wind's variability in that wind output varies more in the sub-hourly to multiple-hour time frame, not on a minute-to-minute basis that is characteristic of regulation. Fast, sub-hourly markets tend to be characteristic of ISOs and RTOs. Areas without ISOs and RTOs generally allow hourly generation schedules only, and most generators have to follow flat hourly schedules set one hour or more in advance. At least in part for this reason, wind integration costs tend to be higher in regions that do not have sub-hourly scheduling as compared to regions that do.

\section{Demand Response}

Shifting load to correspond to periods with high wind production may help avoid curtailment of wind generation and help manage conditions of high wind generation or times of low or minimum load. To date, demand response programs have been designed for reducing peak electricity demand or for allowing customers to self-generate using distributed generation, also during times of peak demand, not for aiding wind integration. One recent instance of using demand response in conjunction with wind production is when ERCOT called on $1200 \mathrm{MW}$ of load response in February 2008 to help remedy falling frequency from an imbalance between generation and load. ${ }^{12}$

\section{Is Storage Necessary for Integrating Wind?}

The U.S. Department of Energy determined that the United States can accommodate as much as $20 \%$ wind power generation without requiring storage. It will be many years before the levels of wind generation will be significant enough in the United States before storage may be needed, and in that time, changes in resource mix, market rules, and the other factors discussed earlier may ease large-scale wind integration without the need for storage technologies. Consistent with this time frame, several storage technologies are at an advanced R\&D or demonstration stage and are not available at a large scale currently. That said, storage systems have recently been installed and/or tested in PJM, NYISO, CAISO, and ISO New England, as well as by American Electric Power and Golden Valley Cooperative in Alaska. These systems were not installed to "back up" wind, but to provide essential grid services such as regulation and voltage support. Indeed, storage should be viewed as providing grid services, not for supporting any individual plant or technology.

\section{Wind Curtailment}

Maximum wind production can be several times larger than average wind production, meaning that at $20 \%$ wind penetration by energy, wind production may equal consumer demand for some hours. More recent U.S. wind integration studies have stated that at higher levels of wind penetration, wind generation may need to be curtailed during some portion of the year, such as during periods of low demand and high wind production. 
Wind curtailment is occurring presently in some regions, in large part because of transmission constraints. ERCOT, for instance, assigns daily limits on wind generation, as there is about 8,000 MW of wind in an area that can accommodate about 4,500 $\mathrm{MW}$ of generation. ${ }^{13}$ NYISO is requiring wind generators to bid an economic offer price. During transmission-constrained hours, NYISO would direct a wind generator to reduce output if the market clearing price drops below the wind generator's economic offer price.

\section{Conclusions}

Wind integration studies have progressed from whether it is possible to incorporate wind generation to focusing on how to do it and at what cost. More wind integration studies are underway. ISO New England, the Southwest Power Pool, the Nebraska Power Association, and NYISO all have wind integration studies underway, and CAISO is evaluating how to incorporate $33 \%$ renewable energy generation. Furthermore, NREL is involved in two significant regional wind integration studies covering the Eastern Interconnection and the Westconnect region of the Western Interconnection that will shed even more light on incorporating higher levels of wind generation. ${ }^{14}$ Finally, NERC will be implementing a number of follow-on activities to its variable generation report, including preparing a reference manual for system operators on operating the grid with large amounts of variable energy generation.

Yet wind integration will not be accomplished successfully by doing "more of the same" - it will require significant changes in grid planning and operations, continued technical evolution in the design and operation of wind turbines, further adoption and implementation of wind forecasting in the control room, and consideration and incorporation of market and policy initiatives to encourage more flexible generation. And given the rapid increase in wind capacity in the United States over the past few years, it may be worthwhile to re-run some wind integration studies with actual wind power production and wind forecast data and determine the difference in study results between the simulated wind data that has been used and actual wind production data. That said, it appears that there are no fundamental and insurmountable obstacles when incorporating greater levels of wind power into the U.S. grid.

\section{Authors' Biography}

Jennifer DeCesaro is a Senior Energy Analyst with Sentech, Inc., a clean energy and energy efficiency consulting company based in Bethesda, Maryland. At Sentech, she supports the U.S. Department of Energy Solar Energy Technologies Program, leading the state and utility technical outreach efforts for the market transformation team. She provides strategic direction on how to further the development of solar markets in the United States through direct outreach to state government officials and utility company executives. Prior to joining Sentech, Jennifer was a senior analyst at Exeter Associates, where she worked on issues with renewable energy integration onto the electric grid and on transmission policy issues. She also has worked for the Clean Energy Group, the National Conference of State Legislatures, the Catamount Institute, and as an environmental consultant in the U.S. Virgin Islands. She holds a B.A. in Environmental Biology from Colorado College and a Master's Degree in Environmental Law from the Vermont Law School. 
Mr. Porter is a Vice President and Principal at Exeter Associates, Inc., with over 25 years of experience in renewable energy technologies, state and federal regulation of the electric power industry, and transmission access and policy. He leads and performs research in the design, implementation, and evaluation of renewable energy policies; on grid integration of renewable energy technologies; and on development and implementation of transmission policies. Mr. Porter's recent work includes studies of the Federal Energy Regulatory Commission's generation interconnection policies, the development of state transmission infrastructure authorities, the performance of state renewable portfolio standards in the Northeastern United States, and state and regional initiatives to develop new transmission. He also led a large study for the California Energy Commission that assessed the feasibility of incorporating up to $33 \%$ renewable energy generation by 2020 . He holds a B.S. in Environmental Studies from Lewis \& Clark College in Portland, Oregon, and an M.A. in Economics from The American University in Washington, D.C.

\footnotetext{
${ }^{1}$ American Wind Energy Association, Wind Energy Grows by Record 8,300 MW in 2008, press release, January $28,2009$.

${ }^{2}$ U.S. Department of Energy, 20\% Wind Energy by 2030: Increasing Wind Energy's Contribution to U.S. Electricity Supply, July 2008, http://www.20percentwind.org/20p.aspx?page=Report.

${ }^{3}$ The North American Mesoscale Model refers to the numerical weather prediction model run by National Centers for Environmental Prediction for short-term weather forecasting. The model is run four times a day $(00,06,12,18 \mathrm{UTC})$ out to 84 hours. It is currently run with 12-km horizontal resolution and with 1-hour temporal resolution, providing finer detail than other operational forecast models. Numerical weather prediction uses current weather conditions as input into mathematical models of the atmosphere to predict the weather. Use of model ensemble forecasts helps to define the forecast uncertainty and extend weather forecasting farther into the future than would otherwise be possible.

${ }^{4}$ Michael Milligan and Brendan Kirby, Calculating Wind Integration Costs: Separating Wind Energy Value from Integration Cost Impacts, National Renewable Energy Laboratory, NREL/TP-550-46275, July 2009, http://www.nrel.gov/wind/systemsintegration/pdfs/2009/milligan_wind_integration_costs.pdf.

${ }^{5}$ California ISO, Integration of Renewable Resources, November 2007, http://www.uwig.org/CAISOIntRenewablesNov2007.pdf.

${ }^{6}$ Western Interstate Energy Board, "Western Transmission Expansion: Proposed Transmission Projects," http://www.westgov.org/wieb/transmission/projects.html, accessed August 28, 2009.

${ }^{7}$ Michael Milligan, Brendan Kirby, Rob Gramlich, and Michael Goggin, Impact of Electric Industry Structure on High Wind Penetration Potential, National Renewable Energy Laboratory, NREL/TP-550-46273, July 2009, http://www.nrel.gov/wind/systemsintegration/pdfs/2009/milligan_electric structure impact.pdf.

${ }^{8}$ GE Energy; The Effects of Integrating Wind Power on Transmission System Planning, Reliability and Operations. Prepared for the New York State Energy Research and Development Authority, March 2005, http://www.uwig.org/nyserdaphase2.pdf.

${ }^{9}$ GE Energy, Intermittency Analysis Project, Appendix B: Impact of Intermittent Generation on Operation of California Power Grid, July 2007, http://www.uwig.org/CEC-500-2007-081-APB.pdf.

${ }^{10}$ GE Energy, Analysis of Wind Generation Impact on ERCOT Ancillary Services Requirements, March 28, 2008, http://www.uwig.org/AttchB-ERCOT_A-S_Study_Final_Report.pdf.

${ }^{11}$ Testimony of Brendan Kirby, Consultant to the American Wind Energy Association, to the Federal Energy Regulatory Commission, March 2, 2009.

${ }^{12}$ Erik Ela and Brendan Kirby, ERCOT Event on February 26, 2008: Lessons Learned, National Renewable Energy Laboratory, NREL/TP-500-43373, July 2008, http://www.nrel.gov/docs/fy08osti/43373.pdf.

${ }^{13}$ A proposal to remove these limits for wind and subject all wind capacity to ERCOT transmission congestion protocols is working its way through the ERCOT stakeholder process.

${ }^{14}$ For more information, see http://wind.nrel.gov/public/EWITS/ for the Eastern Wind Integration and Transmission Study and http://wind.nrel.gov/public/WWIS/ for the Western Wind and Solar Integration Study.
} 


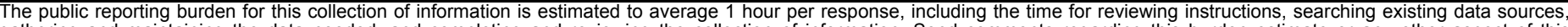

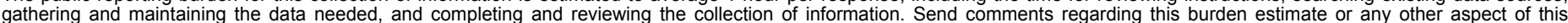

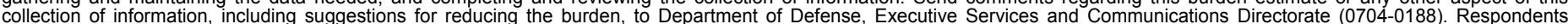

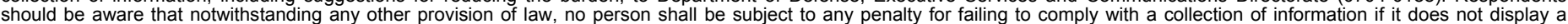

should be aware that notwithstanding

PLEASE DO NOT RETURN YOUR FORM TO THE ABOVE ORGANIZATION.
1. REPORT DATE (DD-MM-YYYY)
2. REPORT TYPE
December 2009
Subcontract Report
3. DATES COVERED (From - To) 2004 - 2008

4. TITLE AND SUBTITLE

Wind Energy and Power System Operations: A Review of Wind

Integration Studies to Date

5a. CONTRACT NUMBER

DE-AC36-08-GO28308

5b. GRANT NUMBER

5c. PROGRAM ELEMENT NUMBER

6. AUTHOR(S)

Jennifer DeCesaro and Kevin Porter

5d. PROJECT NUMBER

NREL/SR-550-47256

5e. TASK NUMBER

WER95501

5f. WORK UNIT NUMBER

7. PERFORMING ORGANIZATION NAME(S) AND ADDRESS(ES)

Exeter Associates, Inc., 5565 Sterrett Place, Suite 310

Columbia, Maryland, 21044

8. PERFORMING ORGANIZATION REPORT NUMBER

LAM-9-99431-01

9. SPONSORING/MONITORING AGENCY NAME(S) AND ADDRESS(ES)

National Renewable Energy Laboratory

10. SPONSOR/MONITOR'S ACRONYM(S)

NREL

1617 Cole Blvd.

Golden, CO 80401-3393

11. SPONSORING/MONITORING AGENCY REPORT NUMBER NREL/SR-550-47256

12. DISTRIBUTION AVAILABILITY STATEMENT

National Technical Information Service

U.S. Department of Commerce

5285 Port Royal Road

Springfield, VA 22161

13. SUPPLEMENTARY NOTES

NREL Technical Monitor: Jeff Hein

14. ABSTRACT (Maximum 200 Words)

This paper provides an overview of the challenges associated with wind integration and summarizes the findings of the wind integration studies conducted over the course of the past five years.

\section{SUBJECT TERMS}

Wind; integration; grid; utilities; RTOs; ISOs; system impacts; transmission; planning

\begin{tabular}{l} 
16. SECURITY CLASSIFICATION OF: \\
\begin{tabular}{|l|l|l|}
\hline $\begin{array}{c}\text { a. REPORT } \\
\text { Unclassified }\end{array}$ & $\begin{array}{c}\text { b. ABSTRACT } \\
\text { Unclassified }\end{array}$ & Unclassified \\
\end{tabular} \\
\hline
\end{tabular}

\begin{tabular}{|c|c|}
\hline $\begin{array}{l}\text { 17. LIMITATION } \\
\text { OF ABSTRACT }\end{array}$ & $\begin{array}{l}\text { 18. } \text { NUMBER } \\
\text { OF PAGES }\end{array}$ \\
\hline UL & \\
\hline
\end{tabular}

19a. NAME OF RESPONSIBLE PERSON

19b. TELEPHONE NUMBER (Include area code) 